Revista Tempos Históricos • Vol. 24, n. 1 (2020) • e-ISSN: 1983-1463

\title{
CRIANÇAS LISTADAS NO LIVRO DO FUNDO DE EMANCIPAÇÃO DA ESCRAVIDÃO NA AMAZÔNIA BRAGANTINA (1876)
}

\author{
CHILDREN LISTED IN THE BOOK OF THE EMANCIPATION FUND \\ FOR SLAVERY IN THE BRAZILIAN AMAZON (1876)
}

\author{
Ketno Lucas Santiago - (PPLSA - UFPA $)^{l}$ \\ Ana Paula Vieira e Souza - (PPLSA-UFPA $)^{2}$
}

RESUMO: No presente texto, tratamos do perfil sócio-histórico de crianças negras escravas, no Livro de Classificação para serem libertas pelo fundo de emancipação à escravidão, de 1876 do século XIX, do acervo público municipal de Bragança, Estado do Pará. Metodologicamente é uma pesquisa histórico-documental com base em fonte histórica que considera os critérios de classificação como nome, cor, idade, sexo, profissão, família, aptidão para o trabalho, valor, nome da família escravista. O estudo revela que o Estado destinou recursos via fundo para os senhores escravagistas, como pagamento para libertar as crianças. O fundo teve amparo legal na Lei 2.040 de 1871 . As crianças negras realizavam trabalho na lavoura, serviço doméstico, olaria. Ainda, que o Estado tenha destinado aos senhores, nem todas as crianças tiveram o direito à liberdade, continuavam sendo exploradas pelos senhores brancos ou sob o poder do Estado.

PALAVRA-CHAVE: Fundo de Emancipação. Criança. Escravidão.

ABSTRACT: In this text, we deal with the socio-historical profile of black slave children, in the Classification Book to be freed by the emancipation fund to slavery, from 1876 of the 19th century, from the municipal public collection of Bragança, State of Pará. Methodologically, it is a historical-documentary research based on historical source that considers the classification criteria as name, color, age, sex, profession, family, aptitude for work, value, slave family

\footnotetext{
* A pesquisa faz parte das ações desenvolvidas no Grupo Estudos e Pesquisa sobre Trabalho e Educação, GEPTE/Linha Trabalho e Infâncias com/sobre crianças, principalmente, pela escassez de discussões históricas em Escolas da Amazônia bragantina. Ainda, parte das análises do Fundo de Emancipação compôs uma subseção na Dissertação de Mestrado, defendida em 2018, no Programa de Pós-Graduação em Linguagens e Saberes da Amazônia (PPLSA/UFPA). ${ }^{1}$ Historiador, Especialista em Educação e Mestre pelo Programa de Linguagens e Saberes da Amazônia da Universidade Federal do Pará do Campus Universitário de Bragança, Pará. Bolsista CAPES. ketnolucas@gmail.com

2 Doutora em Educação, Professora da Universidade Federal do Pará, do Programa de Linguagens e Saberes da Amazônia. paulladesa@ufpa.br
} 
name. The study reveals that the state has alded funds through the funds for slave rs, as payment to free the children. The fund had legal protection in Law 2040 of 1871. Black children performed work in farming, domestic service, pottery. Furthermore, that the State had destined for you, not all children had the right to freedom, continued to be exploited by white lords or under the power of the State.

KEYWORDS: Emancipation Fund. Child. Slavery.

\section{Introdução}

A presente pesquisa a respeito do Livro do fundo de emancipação datado de 1876 é resultado do Projeto de Pesquisa subsidiado pelo Programa Institucional de Bolsas de Iniciação Científica e do Programa de Apoio ao Doutor Pesquisador (PIBIC/PRODOUTOR) ${ }^{3}$ compondo ações do Grupo de Estudos e Pesquisas sobre Trabalho e Educação, Linha Trabalho e Infâncias, que se debruça em pesquisar as culturas infantis, história do recreio, o brincar, trabalho infantil e a construção histórica das infâncias na Amazônia paraense.

Partimos da compreensão da existência de muitas infâncias, com base na historiografia do Brasil, para quem sempre existiu um sentimento de infância no contexto brasileiro, marcada também, por "sofrimento e violência". As narrativas historiográficas revelam a existência de "dolorosas separações entre pais e filhos", existia uma "preocupação com o destino dado aos seus filhinhos de coração".

No Brasil do Século XVII existiu um cuidado com as crianças, ainda que esse período representasse uma "sociedade pobre e escravista", pois as mães negras em condições de escravas lutavam para impedir a partida de seus filhos para lutar na Guerra do Paraguai. Elas sofriam por não poder amamentar as suas crianças, por serem obrigadas a dar de mamar para a criança da Casa Grande (DEL PRIORE, 2008: 11).

\footnotetext{
${ }^{3}$ No ano de 2017, o GEPTE Linha Trabalho e Infâncias ampliou as ações para o Campus Universitário de Bragança da Universidade Federal do Pará, submetendo dois Projetos de Pesquisa PIBIC, PIBIC/PRODOUTOR (2017-2018), Culturas infantis em comunidades no entorno de manguezais: discurso de crianças da Amazônia bragantina entre brincares e brincadeiras.
} 
Ao considerar a historiografia brasileira a respeito da constituição de infâncias, datada historicamente ora pelo limite da idade, mortalidade, fome, miséria, guerras, escola, cuidado, maus tratos, violência, ora por questões do trabalho de crianças no período duradouro da escravidão no Brasil. Os membros da Linha Trabalho e Infâncias localizaram no acervo público municipal de Bragança um conjunto de documentos, dentre eles o Livro de Emancipação de 1876 com registro de crianças aptas para o trabalho, portanto, o interesse em analisar a classificação indicada as infâncias como possíveis libertas.

Para compreender esse contexto histórico de políticas envoltas do fundo de emancipação da escravidão de crianças e adultos registradas no Livro da Comarca de Bragança, na segunda metade do Século XIX, faz-se necessário observar o contexto político do Brasil no período da regência do Império Monárquico. O sistema escravocrata à época, aviltante, tardio, em declínio, posteriormente, a 1876, doze anos, ocorreu a abolição da população negra escravizada no país.

No Brasil, o longo período da escravidão, do Brasil Colônia até o período histórico do Brasil Império, deve ser compreendido por vários aspectos, econômico, político, social entre outros, sobretudo, com destaque para a presença da população negra do Continente África, forçados ao trabalho escravo, em todos os setores da economia brasileira, principalmente, no campo da agricultura e de mineração. O mercado de trabalho forçado cumpriu o papel de promover o processo de colonização por parte dos europeus na apropriação de terras na atividade laboral da monocultura.

O Século XVIII é marcado pelo enfraquecimento da política escravista, fruto das políticas do movimento abolicionista e de interesses econômicos com a gênese das revoluções, são elementos determinantes para as mudanças ocorridas em países como Inglaterra e França. Nesses países um conjunto de ações no campo das ideias pelo mundo, as chamadas "Era das Revoluções", identificadas como a revolução industrial, a revolução francesa, conforme aponta (HOBSBAWN, 2015), que influenciaram as lutas populares, 
principalmente, os ideais libertários, de independência e abolicionistas pelo mundo.

Diversas manifestações populares foram influenciadas por esses ideais no Brasil, em 1789 a Inconfidência Mineira, em 1798 a Conjuração Baiana e em 1817 a Revolução Pernambucana, a Cabanagem no Pará em 1835, entre outros movimentos de independência que ocorreram nesse período (COSTA, 2007: 32). As duradoras lutas e rebeliões ocorreram no país com a participação de pessoas escravizadas, com a participação de negros, de caboclos, indígenas etc., marcado historicamente entre o final do século XVIII e início do XIX.

As transformações sócio econômicas e políticas motivadas pela maquinaria da revolução industrial na Inglaterra, passou a exigir dos países, inclusive do Brasil, outro modo de produção do trabalho humano, formar um novo tipo de homem no dizer de Gramsci (2011), o trabalho assalariado. São conceitos para inculcar novos ideais no campo político para gerar a ampliação do mercado de consumo. Era preciso expandir, escoar a produção por meio de uma mão de obra assalariada, um novo formato de exploração do sistema capitalista (COSTA, 2007).

Esses elementos são os motivadores de a Inglaterra impor ao comércio bloqueios, pressionar o Governo Imperial pelo fim da escravidão como força de trabalho. Os vários conflitos de interesses entre classes, formada por moradores da metrópole, comerciantes e proprietários de fábricas, eram contrários aos interesses dos senhores escravagistas agricultores. Certa vez no parlamento, um deputado Fluminense, senhor Rodrigues Torres defendeu os interesses dos donos da agricultar, "se não tomarmos alguma providência que proteja os interesses agrícolas, única indústria no Brasil, ficaremos a bem depressa reduzidos à classe operária ${ }^{4}$ (MATTOS, 2004: 47).

O conflito de interesses do setor dominante do Brasil marca o período histórico oitocentista, em manter o sistema perverso da escravidão, que segundo Moura (1994) se dividiu em duas fases, uma antecede o ano de 1850, o

\footnotetext{
${ }^{4} \mathrm{O}$ autor Ilmar Mattos (2004), faz referências aos Anais do Parlamento Brasileiro, Câmara dos Deputados, Sessão de 11 de agosto de 1843, p. 717.
} 
"escravismo pleno5", e, a segunda fase com a publicação da Lei Eusébio de Queiroz, No 581 de $1850^{6}$. Essa Lei estabeleceu medidas para restringir o tráfico de negros do Continente África, o "escravismo tardio ${ }^{7}$ ".

O declínio da escravidão no Brasil é impulsionada por Leis e Decretos que estabeleceram marcos regulatórios para limitar a prática escravista no país (BRASIL, 2012). A Lei do Governo Feijó de $1831^{8}$ estabeleceu o fim do tráfico e considerava livres todo negro vindo de fora. A Lei Eusébio de Queiroz, No 581 de 1850, proibiu o tráfico de pessoas do Continente África. Muitos "traficantes estrangeiros foram expulsos do país e as autoridades reforçaram a fiscalização" (COSTA, 2007: 287). Outras Leis ${ }^{9}$ foram aprovadas no Brasil Império punindo navios que transportassem pessoas do Continente África.

Desses conjuntos de legislações constituídas no Brasil Império, destaca-se a Lei do Ventre Livre, № 2.040, de 28 de 1871, por declarar livre os filhos de mulheres escravas, nascidos a partir da publicação dela. A Lei do Ventre Livre indicava libertos os filhos de pessoas escravas da nação e outros países; ainda estabelecia a forma de criação e tratamento daqueles filhos menores e a libertação anual de escravos com a aprovação do Fundo de Emancipação da Escravidão.

Enfatizar a Lei do Ventre Livre tem o sentido de compreender o Fundo de Emancipação da Escravidão como instrumento dessa Lei, que contribui para o entendimento de libertar-se do outro, do sistema de exploração. Uma Lei composta por dez artigos, conforme enuncia o manuscrito original da redação final do projeto de Lei encaminhando ao parlamento brasileiro à época.

\footnotetext{
${ }^{5} \mathrm{O}$ escravismo pleno indicava "as relações entre os homens no processo de trabalho continuaram atrasadas e correspondentes a um estágio anterior (MOURA, 1994: 52).

${ }^{6}$ Lei Eusébio de Queiroz. Estabelece medidas para a repressão do tráfico de africanos neste Império. (BRASIL, 2012: 159).

7 O escravismo tardio, foi um período marcado por um conjunto de medidas, que enfraqueceram o sistema escravista. Lei para proibir o tráfico da população negra. Investimentos financeiros para outros setores econômicos; construção de Bancos, ferrovias, linhas de telégrafos e outros.

${ }^{8}$ Lei do Governo Feijó, de 7 de novembro de 1831. Declara livres todos os escravos vindos de fora do Império, e impõe penas aos importadores dos mesmos escravos (BRASIL, 2012: 69).

${ }^{9}$ Lei $\mathrm{N}^{\circ} 731$ de 1854 . Decreto $\mathrm{N}^{\circ} 3.310$ de 1864 , concedeu emancipação dos africanos do Império. Lei $\mathrm{N}^{\circ} 1.237$ de 1864 tratou dos escravos pertencentes às propriedades agrícolas como objeto. decreto $\mathrm{N}^{\mathrm{o}} 1.695$ de 1869 , proibindo a venda de escravos em pregão e em exposição pública (BRASIL, 2012).
} 
A Lei do Ventre Livre enuncia a respeito do tratamento dado aos filhos de pessoas escravizadas com idade até oito anos, pois estabelece outra interpretação, a partir dessa idade, o senhor de escravo tinha a opção de devolver para o Estado, ainda receber uma indenização no valor de 600\$000, bem como, de explorar a força de trabalho de crianças até a idade de 21 anos (BRASIL, 2012: 527).

Figura 1 - Texto original da Lei $N^{\circ} 2.040 / 1871$ encaminhado ao Senado Federal.

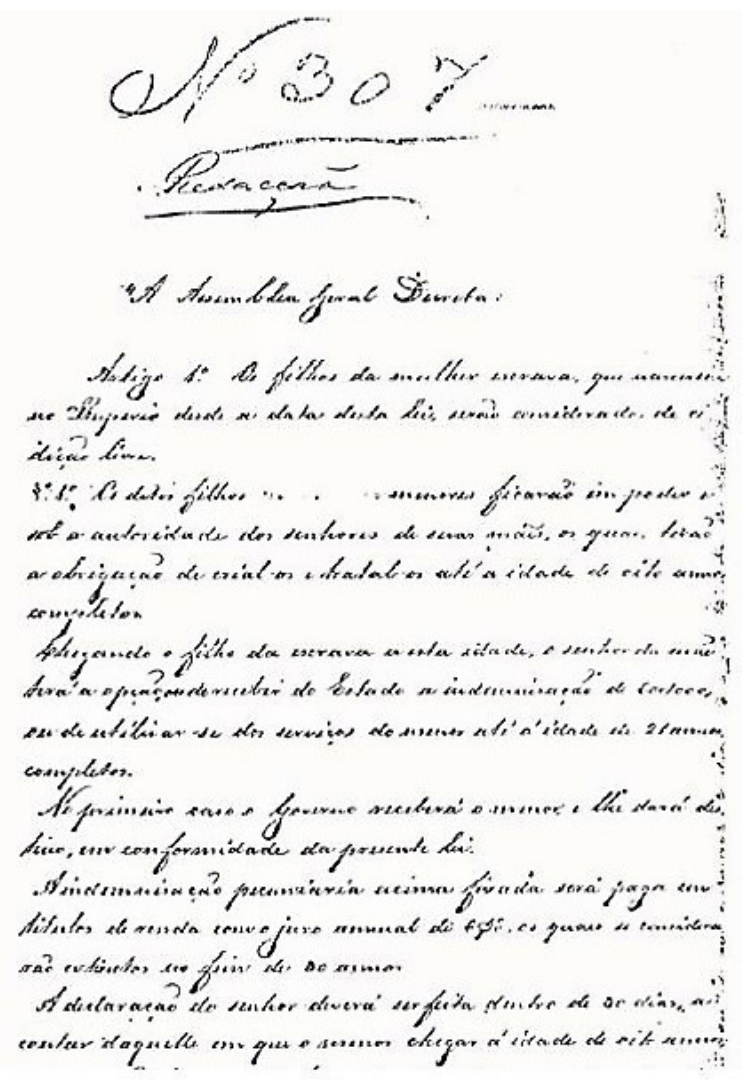

Fonte: Imagem extraída do livro (BRASIL, 2012: 531).

As comarcas recebiam recurso do Império para dar amparo legal a Lei do Ventre Livre e constituírem o Fundo de Emancipação a Escravidão, que favorecia o senhor dos escravos. Emancipar, se liberta historicamente foi movido por resistências e enfretamentos do negro contra os senhores brancos, pois o Fundo de Emancipação da Escravidão no contexto histórico da Lei de 
1871, manteve os interesses de classes, pois eles controlavam a liberdade dos negros escravos.

A emancipação assim como o fim do sistema escravocrata foi moroso, controlado pelo Estado e pelos interesses de senhores, todavia os negros atuavam em defesa da sua liberdade, lutas e resistências fizeram parte dos seus discursos, de outro modo, os senhorios insistiam em adiar o fim da abolição. Esse período histórico de debates no Brasil culminando na aprovação da Lei do Ventre Livre, uma política de controle garantida pelo poder estatal brasileiro, sobretudo, em determinar quem seriam os libertos será implementada pelo fundo.

O fundo de emancipação da escravidão mostrou os interesses díspares, de um lado o de manter a servidão, de outro enfrentar para se libertar do sistema servil. Com isso, muitos processos contra a forma de classificação dos negros escravizados, os possíveis libertos. Esses enfretamentos da população escravizada foi pautado na Lei de 1871 que garantia a eles a sua emancipação.

Por isso, o estudo e reflexões sobre o Fundo de Emancipação da Escravidão a respeito das infâncias negras no contexto da Amazônia bragantina nas pesquisas da Linha Trabalho e Infâncias é pautado na historiografia, pois é compreender a construção do fundo permeada por conflitos de interesse econômico, bem como, o de desvelar a história de crianças negras subsumidas ao trabalho forçado. Ainda, significa mostrar que elas também fizeram parte da população negra escravizada do Continente África e serviram de base para o desenvolvimento econômico da Região Amazônica no sistema escravagista.

\section{População negra na Região Amazônica}

A Região Amazônica formada pelos "Estados do Pará e Maranhão e abrangia o Ceará, Piauí [...] até os Estados do Amazonas e Acre, com áreas de fronteiras com Roraima, Rondônia e Amapá” (GOMES; SCHWARCS, 2018: 107). Todavia, a inclusão definitiva da Amazônia ao espaço geográfico do dia a dia do português na América, segundo Salles (2005) somente ocorreu em 1616, com a fundação da cidade de Belém, conforme mostra o mapa da figura 2. 
Figura 2 - Capitania do Grão-Pará.

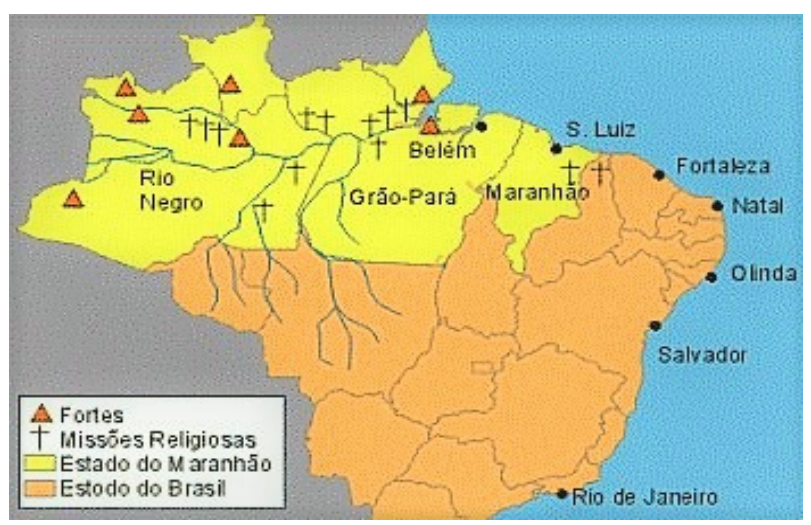

Fonte: http://twixar.me/Ds0K

Na Província do Grão Pará não foi numeroso as pessoas negras escravizadas de origem do Contingente África, como no Maranhão. Em “1830 mais de 20.514 africanos foram trazidos para o Grão-Pará" (GOMES; SCHWARCS, 2018: 111). Na Região Amazônica "cerca de 58.895 pessoas do Continente África submetidas ao sistema de exploração da força de trabalho, os escravos cativos africanos" (BEZERRA NETO, 2012: 202). Os trabalhos forçados eram nas cercearias da cana de açúcar.

Todavia, "a história da escravatura africana no Pará se escreveu com os mesmos processos, determinando, como em toda parte, as mesmas reações do escravo". Os negros submetidos ao trabalho na lavoura da cana de açúcar e nos engenhos contribuíram para a economia se expandir. Na Província do Grão Pará existiu uma política social de povoamento diferente de outras regiões do Brasil, com semelhança da Região da Amazônia. A Província do Amazonas, se destacou por constituir uma população no geral, dividida entre pessoas livres e escravizados, livres entre adultos e crianças, correspondendo "21.982", e no sistema servil - adultos e crianças correspondiam ao quantitativo de "700" pessoas (COSTA, 2016: 52).

Uma caracterização da Província do Grão Pará foi o número de matrículas de pessoas escravas pela Lei do Ventre Livre, "19.729”. Todavia, “o censo geral do Império" contabilizava "27.199" pessoas cativas ${ }^{10}$, portanto

\footnotetext{
${ }^{10}$ Dissertação de Mestrado da Universidade Federal do Pará, 2015.
} 
representou uma diferença de "7.470"11 (LOBO, 2015: 24). Essa discrepância no registro da história do Brasil, limita quantificar os inscritos no Fundo de Emancipação no Estado do Pará.

Pesquisar a história do negro na Amazônia paraense para se pensar a respeito do registro de classificação de crianças no Livro do Fundo de Emancipação, não como uma situação isolada, mas no contexto da escravidão do adulto, de famílias escravizadas, no cenário da política abolicionista, na luta e resistência do negro pelas fugas, para compreender uma determinada classificação de práticas constituidoras elementos que indiquem que uma criança de 4 anos tem aptidões para o trabalho na lavoura, no trabalho doméstico uma prática carregada de interesses de classe, de poder, de força política, na Amazônia bragantina.

\section{Caminhos da Pesquisa}

Na leitura crítica do documento do Livro do Fundo de Emancipação municipal de Bragança localizou-se registros de pessoas indicadas a serem libertas ou não, pois o documento apenas classifica as pessoas pelo nome, idade, profissão, aptidões etc., sem evidenciar a emancipação. Assim, faz-se necessário contextualizar o movimento de emancipação no Brasil, um aliado em prol da luta, do enfretamento e da liberdade com a promulgação da Lei do Ventre Livre de 1871, entre outros embates partindo dos negros escravizados na resistência ao poderio do senhor.

Nesse contexto histórico, de se analisar o destino dado as crianças negras, na classificação do Livro do Fundo de Emancipação da Escravidão, com destaque para as características atribuídas pelos brancos às infâncias negras.

Para isso, metodologicamente a pesquisa historiográfica, na leitura crítica e análise de documento físico, do tipo de abordagem qualitativa com dados quantitativos, uso da técnica de dados estatísticos para mostrar a faixa

\footnotetext{
${ }^{11} \mathrm{O}$ autor se refere ao número de escravos matriculados extraído do Livro do Estado Servil e a Respectiva libertação, Luiz Francisco da Veiga. 1876. BDSF.
} 
etária de crianças, a cor da pele atribuída a elas, profissão, aptidão para o trabalho, o valor de venda, os nomes dos senhores escravagistas de Bragança.

$\mathrm{Na}$ visita ao arquivo municipal em 2017, nos deparamos com um rico material histórico, em condições de leitura e de manuseio. Nas várias idas ao acervo para garimpar documentos localizou-se outros Livros do Fundo de anos anteriores, interessou o ano de 1876, por historicamente ser fonte documental sem modificação tecnológica. Os Livros de 1874 já tinha sido alterados, estavam digitados.

Após a escolha do Livro do Fundo de 1876, criou-se uma agenda de visita com o historiador responsável pelo espaço, as visitas ao espaço ocorriam duas vezes por semana para a leitura do material no campo empírico e as anotações relacionadas as crianças. A leitura não foi de fácil assimilação devido o tipo de escrita, muitas vezes recorremos ao historiador do acervo.

A luz da teoria do círculo de Bakhtin interessava para a análise dos dados as discursividades que permeiam o documento, o contexto histórico, em que condições se escreveu o Livro, o sentido de classificação de crianças, interessa observar o dito e o não dito em uma fonte documental. As muitas vozes que atravessam os enunciados do documento do Livro do Fundo de Emancipação.

Com as devidas anotações, a organização dos dados para tabular as informações extraídas do texto, originando as categorias de análise conforme as variáveis. Tem o sentido de compreender a forma como no Livro do Fundo de Emancipação os senhores de Bragança perceberam as crianças negras, filhas, filhos de pessoas escravizadas. É preciso enunciar como as crianças são classificadas no Livro, quais são as aptidões de crianças negras, quais as idades dessas crianças listadas aptas para trabalhar na lavoura, no trabalho infantil doméstico, o valor pago pela liberdade de uma criança contemplada por outras Leis, mas ainda em cativo.

O discurso para Souza (2014) tem o sentido de conjunto de enunciados marcados pelas regularidades, mas que pode aparecer discursivamente com sentido diferente, se define pela sua relação com o discurso ideológico em um 
contexto social e histórico. O discurso ideológico no dizer de Souza (2014) apresenta discursividades, é constituído por representações relacionados as lutas de classes, por isso para a autora, o enunciado do texto é carregado de um outro discurso, muitas vozes que significam o sentido das relações estabelecidas nas interações sociais.

Esses foram os critérios utilizados para a análise da pesquisa, o de identificar as características atribuídas às crianças negras no Livro do Fundo de Emancipação da Escravidão.

Infâncias e Crianças no registro do Livro do Fundo de Emancipação da escravidão na Amazônia bragantina

É na modernidade, que a infância é considerada uma construção social. Para Souza (2009) a criança é uma construção histórica e vivenciada por fases geracionais, em movimento conforme modifica a idade. No cenário contemporâneo brasileiro, a criança é compreendida como sujeito ativo e participativo da sociedade, um ser histórico-cultural, com direitos garantidos nos dispositivos legais que devem protege-las. "A criança é legalmente amparada e tem direito à educação, direito à liberdade" (SOUZA, 2009: 45).

No Brasil, o reconhecimento da criança lhe garante o direito de brincar, do lazer e de se desenvolver de forma plena. Para Souza (2009) toda criança deve vivenciar o tempo das infâncias, tendo como princípio o brincar, porque propicia a elas vivências e experiências do universo infantil, do mundo do adulto e da natureza, pelo brincar elas se apropriam da cultura do adulto e criam as culturas infantis.

No Brasil muitos ordenamentos jurídicos mencionam o sujeito infante, mas o reconhecimento de infância e criança são garantidos com a redemocratização do país com a Constituição Federal de 1988 e o Estatuto da Criança e do Adolescente de 1990. Eles estabelecem que a criança e o adolescente têm direito a proteção à vida e à saúde, direito de viver me família, condições dignas de existência.

E, a Lei do Ventre Livre de 1871 estabeleceu aos filhos da mulher escrava nascido no Brasil Império, a condição livre (BRASIL, 2012), bem 
como, de ficarem em poder dos senhores e de suas mães até a idade de 08 anos. Nesse sentido, aparece o "ingênuo", na fronteira entre a liberdade e a escravidão. "[...] em 1888 o ingênuo passa a ser tratado como órfão” (LOBO, 2015: 24).

Ocorre que a Lei do Ventre Livre foi atravessa pelo discurso ideológico do Estado, o de determinar condições para libertar o filho de uma mãe escrava na idade de 08 anos. A criança não se emancipava apenas pela idade, dependia de o senhor escravista optar por receber uma indenização do Estado, no valor de 600\$000, a outra escolha pautava o trabalho, o de explorar a força infantil dos 08 anos até os 21 anos.

Além de o senhor escravista ter a opção de emancipar ou explorar, cabia a ele o direito de escolher que serviços as crianças negras estariam aptas para realizar a partir dos 8 anos de idade. O senhor era indenizado pela "criação" de crianças negras. O fato é que os senhores quase sempre optavam em libertar a criança após 8 anos.

No Brasil Império a infância de crianças negras escravizadas foi determinada pela idade de 8 anos, logo deviam deixar as brincadeiras para o trabalho como pagamento da sua alimentação. $\mathrm{O}$ país alcunhou vários termos para dizer de crianças, de "cria da casa" um "protegido privilegiado do senhor que o tem em sua casa" (MATTOSO, 1991: 128). Os termos moleque e moleca "indicavam que a criança tinha entre treze e quatorze anos" (NEVES, 1993: 56). Na Lei do Ventre Livre de 1871 a infância é criança é considerada menor de idade ou de menor ingênuo.

Conforme se observa na história social da infância no Brasil, as legislações não trataram a categoria criança, do contrário utilizaram termos estereotipado para representar o sujeito infantil. Esse tempo histórico entre o período colonial e imperial é marcado pela alta de taxa de mortalidade infantil, do abandono, da falta de cuidados, ausência de afeto, vários tipos de doenças e maus tratos às crianças negras filhas de mães escravas.

Os discursos ideológicos manifestados nos documentos oficiais do Brasil recorrentemente utilizaram a expressões "meúdos", "ingênuos", 
“infantes" para expressar a criança negra (PRIORE, 2008: 84). Nas discursividades da sociedade de classes a infância significou um tempo sem relevância, um momento de transição, um ser que precisava ser salvo da criminalidade, alguém para o futuro. As infâncias de crianças negras historicamente no Brasil são marcadas pelo sofrimento, castigos, abusos, o trabalho como algo natural, de negação do ser criança.

Por isso, considerar o Fundo de Emancipação como um instrumento viável, um elemento a mais para a conquista da liberdade de crianças negras filhos de mães escravas significou algo legítimo. Ainda, que a Lei do Ventre Livre e do Fundo de Emancipação manifeste um caráter de liberdade controlada pelo Estado e pelos senhores escravistas, garantia indenizações e do negro recorrer ao processo de liberdade.

Além da utilização do pecúlio para compra de alforrias diretamente dos senhores conforme Costa (2007) mostra o Fundo contribuiu no processo de emancipação, libertou um número de pessoas escravas. Todavia, o Fundo de Emancipação da Escravidão na Província do Grão Pará não representou um número significativo na libertação homens, mulheres e crianças, o interesse do estudo.

Considerando como referência "a primeira redistribuição do Fundo de Emancipação de 1875, a Província do Pará possuía $22.924^{12}$ escravos”, todavia, “[...], constam terem sido classificados apenas 3.830 escravos”, [...] 7\% da população escrava matriculada" (NEVES, 2014: 133). Em Bragança entre 1874 e 1876 são mais de 30.000 a população de $\operatorname{escravos}^{13}$ (BRASIL, IBGE, 2000). Esses números contribuem para a compreensão de uma série de variáveis, quantitativo e social na análise de crianças classificadas no Livro do Fundo da Amazônia bragantina.

\footnotetext{
${ }^{12}$ Pedro Monteiro Neves, Dissertação de Mestrado Liberdade sem sustos, nem inquietações: significados e sentidos do Fundo de Emancipação no Grão-Pará (1871-1888) do Programa de História Social da Universidade Federal do Pará, 2014. Ver Dissertação sobre o Relatório da Presidência da Província do Pará, 15 de fevereiro de 1876, p. 53-54.

${ }^{13}$ Fonte: REIS, J. J. Presença Negra: conflitos e encontros. In: Instituto Brasileiro de Geografia e Estatística. Brasil: 500 anos de povoamento Rio de Janeiro, 2000: 91.
} 
Figura 3 - Livro do Fundo Municipal de Emancipação da Escravidão.

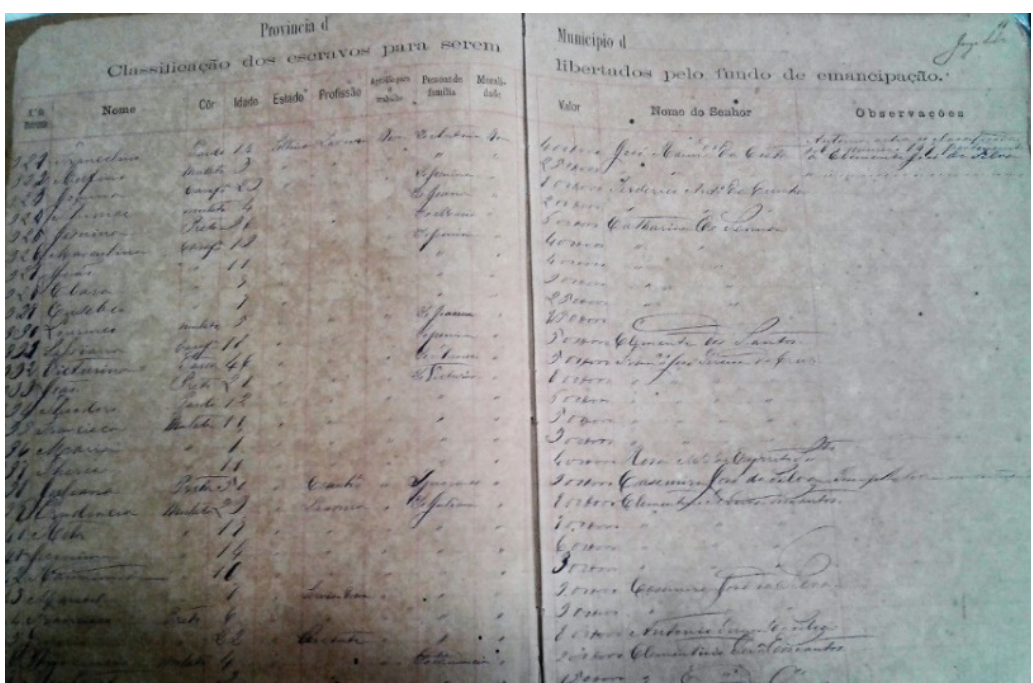

Fonte: Arquivo Público Municipal de Bragança.

O não cumprimento da lei que destina o Fundo de Emancipação a Escravidão, provocou o movimento abolicionista, que não viu o fim da escravidão em processo, neste sentido procurou expandir as suas mobilizações e discussões acerca da ampliação de medidas emancipacionistas. No dizer de Costa (2007: 337) "Rui Barbosa calculava que, se fossem esperados os efeitos da lei, a escravidão só estaria extinta nos meados do Século XX”. Isso reflete o quão ainda estava longe de chegar ao fim da escravidão no Brasil.

Considera-se portanto, a Lei $\mathrm{N}^{\mathrm{o}} 2.040 / 1871$, no dizer de Nabuco (2010) visou "a extinção da escravatura dentro de um prazo de meio século", ou seja, acreditava que a lei era um processo e que ao longo dos anos a escravidão iria se acabar, porem o processo não estava se dando assim, para o autor não existia contradição, a extinção da escravidão poderia ser decretada no presente, por isso defendeu a libertação imediata dos escravos, não somente como medida paliativa em longo prazo, defendeu o Brasil "passar por um processo de purificação da escravidão" (NABUCO, 2010: 82).

Assim, o Fundo de Emancipação a Escravidão por meio de emenda é ampliado para algumas províncias do Brasil Império. No Pará, os efeitos da Lei de 1871 transformaram a Província do Grão-Pará, em uma verdadeira bagunça, 
um "Panamá". Esse termo cunhado por Salles (2005) tem relação com a forma utilizada pelo Fundo para definir os critérios de distribuição dos recursos, "duvidosos". Para o autor "o critério quantitativo era levado em conta para fazer a distribuição, do crédito de 35:739\$440, concedido por aviso do Ministério da Fazenda”, em 1875, para libertar a população escrava (SALLES, 2005: 317).

A Província do Pará, no cenário político local e internacional contribuiu para o início do processo de abolição da escravidão, em caráter oficial no Império, os fatores internos também contribuíram para ocasionar lutas e conflitos entre classes sociais e a atuação do movimento abolicionista, que lutou em favor da libertação de escravos.

Os conflitos regionais em prol do movimento de libertação como a Revolução Cabana, um movimento revolucionário no dizer de Bezerra Neto (2012), pois existiu ruptura da ordem estabelecida e garantiu a tomada de poder por parte da população descontente com a forma de governo da Província do Grão-Pará, defendiam a deportação de todos os portugueses e a destituição de todos os funcionários públicos contrários a independência em defesa de questões sociais e a libertação dos escravos.

Na Província do Pará, no dizer de Salles (2005) a Lei do Ventre Livre teve critérios duvidosos representando um efeito propagandista, pois a província possuía 22.956 escravos matriculados em 1875 sobre os quais foram aplicados mais de 56 contos de réis do Fundo de Emancipação e que poderiam libertar 93 escravos se fossem gastos em média 600 mil réis por cada um. Uma quantidade irrisória diante do grande número de escravos inscritos no fundo.

O Livro do Fundo de Emancipação da Escravidão, na comarca de Bragança no ano de 1876, registrou 804 pessoas, como possível classificação para a conquista da liberdade - corresponde 624 homens e mulheres e 180 crianças (meninos e meninas) em condição de escravidão.

As crianças negras corresponderam 30\% do número total de pessoas classificadas para a emancipação. Do total de 180 crianças, 87 são crianças do sexo masculino e 93 crianças do sexo feminino. Conforme gráfico. 
Gráfico 1- Meninos e Meninas Escravos classificadas no Livro do Fundo de Emancipação.

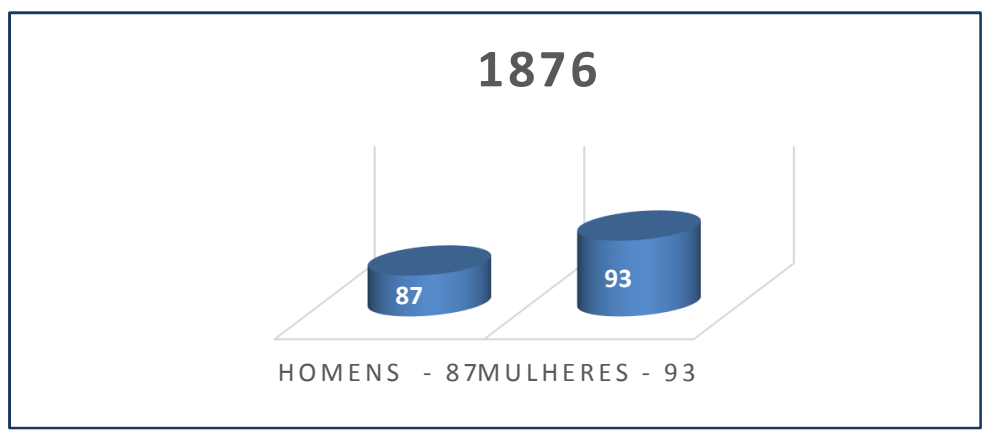

Fonte: Livro de Classificação de Escravos pelo Fundo de Emancipação de 1876.

Conforme observa-se no gráfico são seis crianças a mais do sexo feminino, que serão diferencias na classificação de aptidões para o trabalho. Outro elemento significativo na caracterização de crianças está relacionado a da tez da pele, pois aparece de etnia, preto, preta, pardo, parda, fula, crioula etc., recorrentemente, nos discursos do Livro são atribuídas às crianças expressões depreciativas como cabocla (o), mulata (o), carafuza (o). Essas discursividades ideológicas por parte dos senhores de escravos nos relatos do fundo tinham um sentido de valor da mercadoria ${ }^{14}$, portanto, caráter aviltante.

$\mathrm{Na}$ história do Brasil a respeito da escravidão, a cor da pele se entrecruza com as discussões do processo de miscigenação, "uma nação multiétnica". Para a autora "a mestiçagem existente no Brasil não só era descrita como adjetivada, constituindo uma pista para explicar o atraso ou uma impossível inviabilidade da nação" (SCHWARCZ, 1993: 11-13).

A definição da cor da pele é resultante da escravidão, pois foi atribuída para caracterizar a pessoa escravizada ou a miscigenação como posição social. "No Brasil, a própria escravidão e as limitações que pesavam sobre o status do liberto convertiam a ordem escravista e a dominação senhorial em fatores de estratificação social” (FERNANDES, 2007 :44), ou seja, indicou mudança social dos mestiços, portanto, mulher, homem e criança de origem africana e seus descendestes.

\footnotetext{
${ }^{14}$ Ver Marx (2010) a força do trabalho como valor da mercadoria, um trabalho como valor de troca. O negro visto como força de trabalho.
} 
Todavia, esse mecanismo podia limitar as possibilidades diante da sua definição, conforme Salles (2005: 105) esclarece, que a mestiçagem era utilizada para definir os cruzamentos entre preto, branco, indígenas, em que "o moreno indicava cor da pele mais clara, mameluco pele mais escura". Todas são formas para depreciar o ser humano.

No Livro do Fundo que trata da classificação de crianças da Amazônia bragantina a diferença étnica mostra o quão foi diversa a mestiçagem na comarca de Bragança. Nesse sentido, a presença indígena na escravidão ocorreu desde a colonização do Brasil, segundo Bezerra Neto (2001: 56) o trabalho forçado dos indígenas serviu "como base da economia [...] primeiramente indígena e depois, ainda no século XVI passou-se a utilizar à negra". A mestiçagem na Região Amazônia esteve relacionada ao indígena, branco e negro.

O Gráfico 03 mostra em números essa caracterização da cor da pele de crianças.

Gráfico 3 - Caracterização da tez da pele.
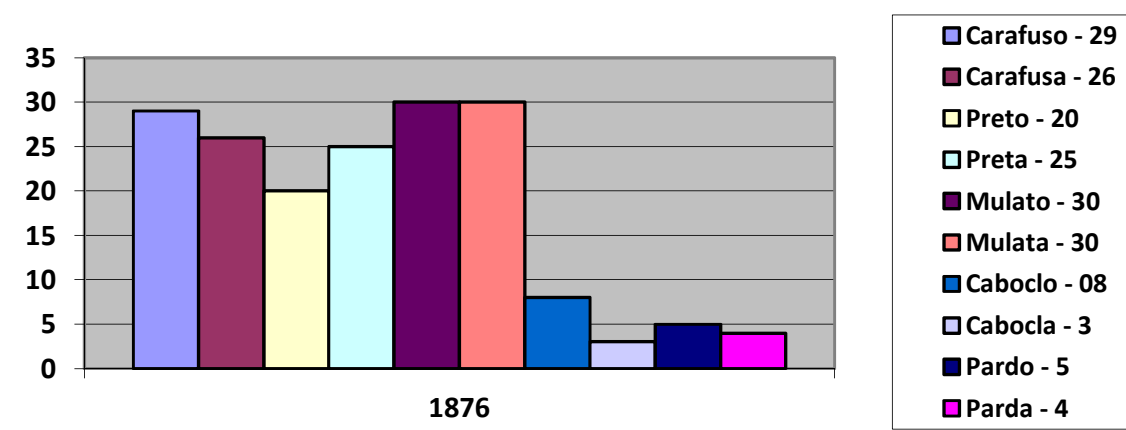

Fonte: Livro de Classificação de Escravos para serem libertados pelo Fundo de Emancipação de 1876.

O processo de mestiçagem também indica a presença de crianças indígenas na Amazônia no sistema da escravidão, elas eram destinadas aos cuidados dos padres.

No Livro do Fundo da Escravidão observa-se outras variáveis como a idade, profissão e aptidões para o trabalho. Em relação a faixa etária delimitamos tendo como base a noção de infância da contemporaneidade e de 
alguns ordenamentos jurídicos do Brasil República do final do século XIX. No Livro são crianças entre 04 e 12 anos classificadas para aceitável emancipação.

Gráfico 4 - Idade de crianças classificadas
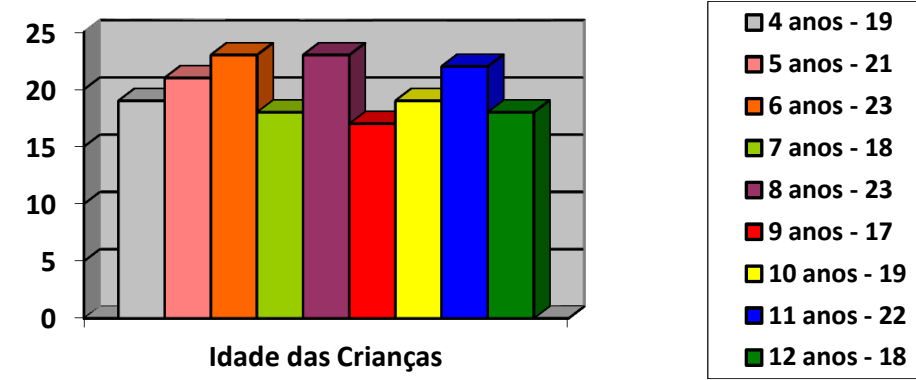

Fonte: Livro de Classificação de Escravos para serem libertados pelo Fundo de Emancipação de 1876 .

A classificação no Livro indica que a criança tinha uma profissão e estava apta para o trabalho. As profissões atribuídas a elas eram pautadas pela atividade da mãe, campo e urbano; trabalho na lavoura, lavagem de roupa, serviço doméstico etc. A comarca de Bragança desenvolvia-se economicamente pelas atividades da agricultura e pecuária, pois o trabalho de negros escravizados foram "responsáveis por fornecer gêneros alimentícios ao Nordeste do Pará" (CASTRO, 2006: 04). Do mesmo modo que o trabalho de criança entrecruzava com o valor estimado pelo fundo, dependendo da profissão, de estar apta, a criança negra representava um valor para as famílias escravagistas de Bragança.

Os enunciados discursivos do Livro do Fundo revelam como as infâncias negras da Amazônia bragantina representavam uma valoração comercial para as famílias donos de escravos, pois essa ideologia atravessada nos escritos da fonte documental ajudam a compreender a negação histórica da infância no Brasil, o preconceito da cor, a integração do negro a realidade cultural da Amazônia do Grão Pará, em que essas crianças vivenciaram as suas relações sociais subsumidas ao trabalho servil, quando na verdade deviam experimentar os brincares, a escola e as culturas infantis (SOUZA, 2014). 
O signo ideológico nos discursos do Livro do Fundo se manifesta ao atribuir a criança negra em plena fase de desenvolvimento cognitivo e social, o peso do trabalho, atividade com sentidos de castigo, sofrimento, um labor árduo, punitivo, carregado de violências, uma forma desumana de olhar para o outro. Nesse sentido, a fonte histórica mostra "desde seu nascimento, a criança negra já encontrava o duro regime da escravidão no encalço da sua vida. Crianças vistas como “duplamente mudas, e duplamente escravas' (MARTINS, 2015: 51).

Ideologicamente, no contexto da escravidão, a criança negra não existia para as famílias escravistas, nem tampouco a infância, uma vez que interessava a esses senhores de escravos, o desenvolvimento da economia, sendo a criança negra a força do trabalho necessário para enriquecê-los.

$\mathrm{Na}$ análise da categoria aptidão para o trabalho, a lavoura é classificada no Livro do Fundo com maior representatividade, todavia, as crianças estavam aptas para o trabalho de lavrador, cozinheira, servente, pedreiro, serviço doméstico e olaria, ou seja, em nenhum momento é descrito não apta ao labor, do contrário tem boa moralidade, obedientes. Para Castro (2006) as crianças em condição de escravidão na atividade doméstica, eram incumbidas de desenvolver várias tarefas durante o dia, ou seja, a exploração da força infantil não tinha limite, elas estiveram submetidas às mais diversas formas de opressão.

A descrição no livro de classificação para as atividades laborais de crianças revela uma discursividade de poder do senhor proprietário de escravos ao classificar crianças entre 04 e 07 anos de idade aptas para o trabalho, pois elas não tinham condições físicas, nem tampouco experiência para desenvolver qualquer tipo de atividade que exige habilidades. O fato é que o trabalho de crianças negras escravas foram "[...] consideradas funções leves” (MARTINS, 2015: 51).

Gráfico 5 - Profissões de Crianças Escravas Libertas pelo Fundo. 

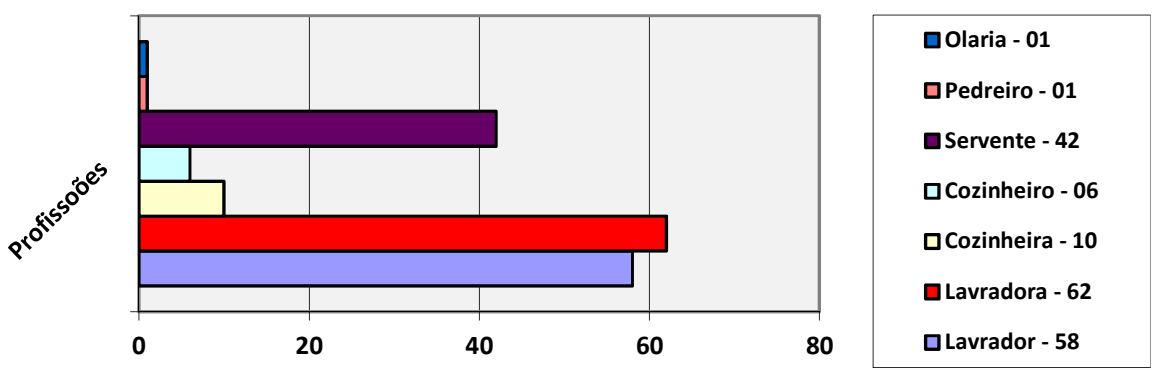

Fonte: Livro de Classificação de Escravos para serem libertados pelo Fundo de Emancipação de 1876

Ao evidenciar as aptidões para o trabalho na lavoura, vimos no gráfico que meninas e meninos nos discursos de senhores de escravos indicavam um quantitativo de 120 crianças e de cozinheira (o) 16, portanto, o trabalho de crianças não se pautou no gênero, ou seja, trabalho de meninas e trabalho de meninos, não importou observar essa fase geracional da infância, apenas o lucro dessa mercadoria. No dizer de Souza (2014: 53), isso fez "com esse tipo de trabalho, historicamente, seja marcado com a dinâmica da pedagogia do capital, cujo caráter é o da disciplina e da punição expressando a persistência de um tipo de exploração do trabalho infantil". Essas profissões na análise de Salles (2005) na maioria das vezes eram consideradas inferiores, negadas pelo homem branco, pois deviam ser realizadas pelos negros escravos, como o trabalho de carniceiro, empregado em matadouro entre outros. Ainda, em Bragança outras produções de gêneros "como tabaco, arroz, feijão, milho, mandioca, mas também de cacau, algodão, gergelim e cana-de-açúcar, assegurada pela mão de obra escrava" (CASTRO, 2006: 15) e pelas mãos das crianças.

Quando se analisa a variável valor os enunciados destacam que o menino tem valor de venda superior as meninas, tem sentidos de que o sexo masculino é mais forte, produtivo e rende mais economicamente, pois a partir dos oito anos de idade tinha vigor para o trabalho, por isso, considerado pelo senhor de escravo como fonte de lucro.

A Lei do Ventre Livre, $\mathrm{N}^{\mathrm{0}} 2.040$ no Artigo primeiro e parágrafo primeiro estabelecia ao senhor escravista a opção de receber uma indenização 
no valor de $600 \$ 000$ por cada criança, bem como tinha o poder de mantê-la sob a sua ordem e explorando a sua força de trabalho até os 21 anos de idade, como forma de pagar o seu próprio sustento (COSTA, 2007).

É evidente, que os senhores donos de escravos optaram pela exploração da força infantil como prestação de serviços, isso significou dizer, que as crianças nascidas livres não mudaram a sua condição com a promulgação da lei, uma vez que continuaram inseridas no sistema escravista. "A exploração de crianças no trabalho atravessa a história do Brasil, desde a colonização, do sistema escravocrata, da urbanização, da industrialização" (SOUZA, 2014: 52).

O fato de a criação do Fundo de Emancipação a Escravidão ter a finalidade de libertar anualmente as pessoas escravizadas, raramente se modificou no Brasil Império, pois o número apenas de "dez mil haviam sido libertos em todo Império pelo Fundo, enquanto as alforrias concedidas espontaneamente por particulares subiam a sessenta mil" (COSTA, 2007: 337).

Quadrro 1 - Valor da venda na lista de classificação do Fundo de 1876

\begin{tabular}{|c|c|}
\hline MÉDIA DE PREÇOS POR IDADE \\
\hline 04 anos & 318,42 \\
\hline 05 anos & 382,71 \\
\hline 06 anos & 480.43 \\
\hline 07 anos & 463,88 \\
\hline 08 anos & 615,21 \\
\hline 09 anos & 544,11 \\
\hline 10 anos & 589,47 \\
\hline 11 anos & 554,54 \\
\hline 12 anos & 688,88 \\
\hline
\end{tabular}

Fonte: Livro de Classificação de Escravos para serem libertados pelo Fundo de Emancipação de 1876.

Nos enunciados extraídos do Livro do Fundo, quanto maior a idade da criança, maior o valor da venda, assim, o valor de crianças escravizadas do sexo masculino representou valores superiores aos de crianças do sexo feminino, portanto, a variação de preço ocorre por sexo e por idade.

Por fim, localizamos no Livro de Registro do Fundo de Emancipação da comarca de Bragança, os nomes dos senhores escravagistas ou proprietários 
de escravos. As famílias com maior recorrência nos registros são Silva, Barreto, Ribeiro, Pinheiros e Pereira. Dentre os nomes dessas famílias segundo Campos (2017) contribuíram para o desenvolvimento econômico local da região, é possível que sim, pois se apropriam da força do trabalho de crianças sem pagamentos salariais, nem despesas alimentares, visto que na escravidão os senhores não se importavam com vidas humanas de negros e negras, nem tampouco das infâncias negras. Para o autor, a construção do poder das famílias esteve ancorada em três aspectos, "matrimônio, família e política", que viabilizaram as posses "das famílias Caetano Ribeiro, Caetano Pinheiro e Andrade Pinheiro" em Bragança-Pará (CAMPOS, 2017: 45).

Assim, considerou-se, a relevância historiográfica da fonte histórica do arquivo municipal de Bragança, que de forma significativa colaborou para que a pesquisa revelasse a história de crianças negras escravizadas no Século XIX, na Amazônia bragantina. Do mesmo modo, o destaque para as várias vozes que emergem da fonte documental, possibilitando ao pesquisador olhar de modo diferente para o contexto histórico diferenciado, entre a história e política liberal que se instalou no Brasil Império passando por diversos aspectos e contextos até chegar ao Brasil República.

\section{Considerações finais.}

Os discursos do Livro do Fundo da Escravidão constituído pela Lei do Ventre Livre, $\mathrm{N}^{\circ}$ 2.040/1871, que se mostrou discursivamente dúbia, raramente, a favor dos interesses de crianças negras escravizadas, um mecanismo para reproduzir e manter a escravidão no Brasil, sem nenhum efeito legal para libertar os escravos, uma vez que dependia da escolha do senhor escravagista.

A Lei de 1871, normalmente optava por manter em seu poder os filhos de escravos até os oito anos de idade, somente após os 21 anos podia ou não ser emancipado, depois de anos de exploração e de trabalho aviltante.

Em 1876, o Livro do Fundo classificou 180 crianças escravizadas para possível conquista da liberdade. Esse número é inferior se comparado com o número de escravos na Região bragantina e em relação ao número de adultos. 
As crianças negras escravas estavam inseridas em relações familiares, por meio de sobrenomes, possível hipótese de relação parental. Ainda, nas análises se identificou a forma que ocorreu em Bragança a exploração da força do trabalho de crianças negras, do modo como as histórias dessas infâncias são negadas na história das políticas educacionais da rede municipal. O modo de trabalho realizado por elas e a condição sub-humana.

Do ponto de vista sócio-histórico, as crianças negras escravas não tiveram escolhas de viverem uma infância longe do sistema de escravidão, a elas foram negadas o direito de escuta, de vida, de escola, do brincar. Historicamente as crianças negras não foram incluídas na sociedade brasileira, reiteradamente, serviram aos interesses dos senhores donos de escravos, sua força de trabalho explorada, viviam humilhadas, em situação de penúria, degradante. Serviam como mercadorias lucrativas aos proprietários escravistas.

Tudo isso coloca outras reflexões e críticas no Campo das Ciências Humanas, diante de uma conflitante e complicada classificação de crianças para com aptidão para o trabalho aos 4, 5, 6 anos de idade. Quanto mesmo vale uma vida de criança negra? É possível localizar na história das infâncias negras de Bragança, se elas e suas mães continuavam a servir os senhores escravistas? Vimos em alguns estudos sobre a história da escravidão na Província do Grão Pará, o quantitativo de negro no sistema servil, e em Bragança é possível localizar fontes que indicam o total de escravo da comarca?

Estes questionamentos indicam a necessidade de outros estudos a respeito da história das infâncias e de crianças negras na Amazônia bragantina de base interdisciplinar Educação e História, sobretudo, para investigar se as crianças classificadas quantas efetivamente foram emancipadas? As fontes analisadas não indicam a liberdade das pessoas classificadas. O estudo de Neves mostrou que em 1875, apenas um negro foi emancipado pelo Fundo.

\section{Referências}

BEZERRA NETO. Escravidão negra no Pará: (Séculos XVII - XIX). $2^{\circ}$ ed. Belém: Paka-Tatu, 2012. 
BRASIL. A abolição no parlamento: 65 anos de luta, (1823-1888) / apresentação do presidente José Sarney. - 2. ed. -- Brasília: Senado Federal, Secretaria Especial de Editoração e Publicações, 2012.

BRASIL. Lei $\mathbf{n}^{\mathbf{0}} \mathbf{7 3 1}$, de 05 de junho de 1854 - punição para capitão ou mestre, piloto ou contramestre de embarcação que fizesse tráfico de escravos. https://goo.gl/FRavkB. Acessado dia 12/03/2019.

BRASIL. Decreto no 3.310, de 24 setembro de 1864, concedendo emancipação a todos os africanos livres no Império. https://goo.gl/Re8vSQ. Acessado dia $12 / 03 / 2019$.

BRASIL. Lei $\mathbf{n}^{\mathbf{0}} \mathbf{1 . 2 3 7}$, de 24 setembro de 1864, considerando os escravos pertencentes às propriedades agrícolas como objeto. https://goo.gl/JbmKg1. Acessado dia 12/03/2019.

BRASIL. Lei $\mathbf{N}^{\mathbf{2}} \mathbf{2 . 0 4 0}$ - de 28 de setembro de 1871. https://goo.gl/1tttxY. Acessado dia 23/03/2018. Acessado dia 12/03/2019.

BRASIL. Decreto no 1.695, de 15-9-1869, proibindo venda de escravos em pregão e em exposição pública. https://goo.gl/UtTudR. Acessado dia $12 / 03 / 2019$.

BRASIL. Decreto no 4.815, de 11-11-1871, regulamentando o art. 60 do $\S 1$ o da Lei 2.040. http://twixar.me/lg8n. Acessado dia 12/03/2019.

CAMPOS, Ipojucan Dias Campos. Bragança (PA): família, política e comércio/ - 1. Ed. São Paulo: Editora Livraria da Física, 2017.

CASTRO, Edna. Escravos e senhores de Bragança (Documentos históricos do século XIX, Região Bragantina, Pará) / Edna Maria Ramos de Castro (Organização). _ Belém: NAEA, 2006.

COSTA, Jéssyka Sâmia Ladislau Pereira. Por todos os Cantos da Cidade. Escravos negros no mundo do trabalho na Manaus oitocentista (1850-1884). Dissertação do Instituto de Ciências Humanas e Filosofia do Programa de PósGraduação em História da Universidade Federal Fluminense - UFF. Niterói. 2016.

COSTA, Emília Viotti da. Da Monarquia à República - momentos decisivos/Emília Viotti da Costa. - 8.ed. ver e ampliada. São Paulo: Fundação Editora UNESP, 2007.

FERNANDES, Florestan. O negro no mundo dos brancos. 2. Ed. Revista - São Paulo: Global, 2007. 
HOBSBAWM, Eric J. A Era das Revoluções (1798-1848). 35º ed. Rio de Janeiro: Paz \& Terra, 2015. P. 5-286.

LOBO, Marcelo Ferreira. Liberdade Tutelada: Ingênuos e órfãos no Pará (1871 -1893). Dissertação do Programa de Pós-Graduação em História da Universidade Federal do Pará - UFPA. Belém. 2015.

MATTOS, Ilmar Rohloff de. O Tempo Saquarema - São Paulo: Huncitee, 2004.

MATTOSO, Katia de Queirós. O filho da escrava (Em torno da Lei do Ventre Livre). Rev. Bras. De Hist. São Paulo, v.8. n. 16, mar./ago. 1988, p.2., p.17. http://twixar.me/vj8n. Acessado dia 13/08/2018.

MARTINS, Lilia Pimentel. Libertações escravas conseguidas através do Fundo de Emancipação e cartas de alforrias em Bragança - Pará (18721888) - 2015, XXVIII Simpósio Nacional de História: Florianópolis-SC, 2015, p 1-11.

MOURA, Clovis. Dialética Radical do Brasil Negro / Clovis Moura. -São Paulo: Editora Anita, 1994.

NABUCO, Joaquim, 1849-1910. O abolicionismo / Joaquim Nabuco. - Rio de Janeiro: Best Bolso, 2010.

NEVES, M. A. M. O fracasso escolar e a busca de soluções alternativas - a experiência do NOAP. Petrópolis/RJ: Vozes. 1993.

NEVES, Pedro Monteiro. Liberdade sem sustos, nem inquietações: significados e sentidos do Fundo de Emancipação no Grão-Pará (1871-1888). Dissertação de Mestrado do Programa de História Social da Universidade Federal do Pará, 2014

PRIORE, Mary Del. História das crianças no Brasil/ Mary Del Priore organizadora. 6.ed. $1^{\text {a }}$ reimpressão. - São Paulo: Contexto, 2008.

SALLES, Vicente. O Negro no Pará sob o regime da escravidão /Vicente Salles - 3 ed. rev. Ampl.- Belém: IAP; Programa Raizes, 2005.

SCHWARCZ, Lilia Moritz. O Espetáculo das Raças - cientistas, instituições e questão racial no Brasil 1870-1930. São Paulo: Companhia das Letras, 1993.

SOUZA, Ana Paula Vieira e. As Culturas Infantis no Espaço e Tempo do Recreio: Constituindo Singularidade Sobre a Criança. 2009. 166 f. Dissertação de Mestrado em Educação - Universidade Federal do Pará, Ciências da Educação, Belém, 2009. 
SOUZA, Ana Paula Vieira e. Trabalho Infantil: discurso de crianças e adolescentes da Amazônia paraense em situação de trabalho. Tese de Doutorado, Belém-PA, 2014.

Recebido em: 31 de outubro de 2019

Aceito em: 10 de junho de 2020 